
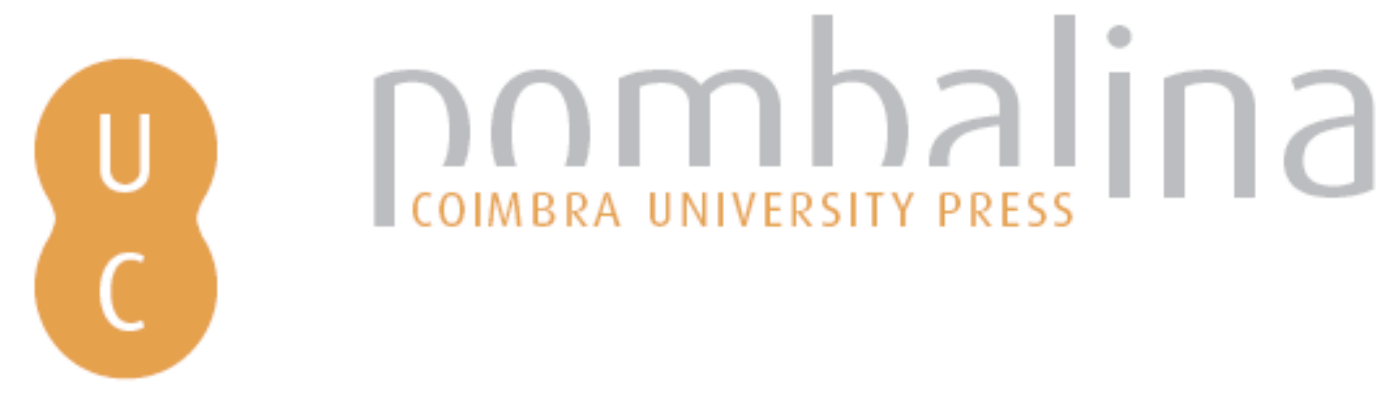

Imagens contorcidas da vida e da morte nos contos de Joaquim Pacheco Neves

Autor(es): $\quad$ Carneiro, Maria do Nascimento

Publicado por: Imprensa da Universidade de Coimbra

URL

persistente: URI:http://hdl.handle.net/10316.2/38705

DOI: $\quad$ DOI:http://dx.doi.org/10.14195/978-989-26-1164-8_28

Accessed : $\quad$ 26-Apr-2023 10:47:53

A navegação consulta e descarregamento dos títulos inseridos nas Bibliotecas Digitais UC Digitalis, UC Pombalina e UC Impactum, pressupõem a aceitação plena e sem reservas dos Termos e Condições de Uso destas Bibliotecas Digitais, disponíveis em https://digitalis.uc.pt/pt-pt/termos.

Conforme exposto nos referidos Termos e Condições de Uso, o descarregamento de títulos de acesso restrito requer uma licença válida de autorização devendo o utilizador aceder ao(s) documento(s) a partir de um endereço de IP da instituição detentora da supramencionada licença.

Ao utilizador é apenas permitido o descarregamento para uso pessoal, pelo que o emprego do(s) título(s) descarregado(s) para outro fim, designadamente comercial, carece de autorização do respetivo autor ou editor da obra.

Na medida em que todas as obras da UC Digitalis se encontram protegidas pelo Código do Direito de Autor e Direitos Conexos e demais legislação aplicável, toda a cópia, parcial ou total, deste documento, nos casos em que é legalmente admitida, deverá conter ou fazer-se acompanhar por este aviso. 
Maria do Nascimento Carneiro

Universidade do Porto ${ }^{1}$

\section{IMAGENS CONTORCIDAS DA VIDA E DA MORTE NOS CONTOS DE JOAQUIM PACHECO NEVES}

Joaquim Pacheco Neves, escritor vilacondense e profícuo autor de contos e novelas, não tem merecido, por parte dos estudiosos da literatura portuguesa, o tratamento e o relevo que a sua obra deveria suscitar. Como tal, este artigo afirma-se como uma proposta de trabalho que visa, ainda que de modo sumário, contribuir para colmatar essa lacuna. O "corpus" que nos ocupa centrar-se-á nas primeiras coletâneas publicadas nos anos 40, a saber:

Contos Macabros (1941)2 e Contos Sombrios (1942) ${ }^{3}$.

Todavia, a obra do autor merece uma abordagem mais ampla e, nesse sentido, julgamos importante completar a análise com textos mais tardios, nomeadamente com História de pobres, de 1978, no sentido de tentar esclarecer se, ao longo do tempo e sob a influência de outros movimentos estéticos, a sua produção permanece apegada às primeiras orientações ou se encontra outros sentidos e responde a outros exemplos formativos.

Indiscutivelmente, como já referimos, Pacheco Neves é, sobretudo, um autor de contos, feitos de uma sucessão de pequenos quadros, espécie de instantâneos de conotações sociais e de vidas cristalizadas em instantes que passam.

Mas, desde as primeiras linhas, é o sentido trágico da existência, o mundo das farsas sociais e as personagens-temas que, linha após linha, entram para o

\footnotetext{
1 («Investigador/a do CITCEM - Centro de Investigação Transdisciplinar Cultura, Espaço e Memória»). Financiado por Fundos Nacionais através da FCT - Fundação para a Ciência e a Tecnologia no âmbito do projecto PEst-OE/HIS/UI4059/2011.

2 Joaquim Pacheco Neves, Contos Macabros, ed. do autor, 1941.

3 Joaquim Pacheco Neves, Contos Sombrios, ed. do autor, 1942.
} 
papel. O leitor convive, de imediato, com um mundo exasperado de dramas, com um universo de teor pessimista, não raro temperado de laivos humorísticos que contribuem para quebrar a intensidade das cenas e das situações.

Assim, quando passamos em revista os próprios títulos, o que desde logo salta à vista é a utilização de um registo terminológico marcado pelo seu quê de infortúnio, de mal, de paixões e de vícios, de ameaças surdas e pesadas, de histórias de imoralidades, de fins trágicos, de mistérios e de terrores. Os títulos funcionam desde logo como protocolo de leitura, implicando marcas de tragédia. Temos, assim, por exemplo: Contos Macabros, Contos Sombrios, Como nasce o ódio, O silêncio e a vida, Histórias do Anoitecer, Histórias do desespero, Histórias da Noite escura, O bairro do cemitério, Histórias de ciúmes, História de uma mulher perdida, História de pobres e Histórias do desencanto.

Os títulos enumerados causam, pois, à partida, um efeito de tensão, visto utilizarem fórmulas de infortúnio e de sofrimento. Longe de embalar a nossa sensibilidade, como se espera muitas vezes dum conto, o autor parece querer tirar o leitor do conforto sereno de uma leitura amena, exagerando os quadros e as situações, obstinando-se a caricaturar, ou seja, a alterar as dimensões, alongando-as e sobrecarregando assim a matéria. De facto, levando ao extremo as situações, Pacheco Neves propõe-se desafiar as medidas da humanidade e da correção ao recorrer a emoções fortes, de feição trágica, a sentimentos que explodem e atiram tudo pelos ares, numa trama viva de conflitos e de paixões, de comportamentos irracionais e alienados.

Julgamos, todavia, possível apontar na sua obra de ficção duas facetas ou tendências. Uma, inspirada ainda numa certa estética já "démodée", que o leva a atualizar alguns dos tópicos do nosso romantismo oitocentista, os quais se refletem na escrita de, pelo menos, duas das coletâneas, acima referidas, e que sugestivamente se intitulam: Contos Macabros e Contos Sombrios.

Uma outra, com textos mais tardios, possui já evidentes afinidades a outras escolas e estéticas.

Pode dizer-se que as primeiras duas coletâneas de contos, evocam, na nossa perspetiva, a corrente ficcional que atravessou a Europa nos finais do século xviı, a qual é habitualmente designada por «literatura negra ou de terror». Com efeito, nestes textos, perpassa uma atmosfera sombria e de horror. Joaquim Pacheco Neves cede aqui ao gosto pelo espetacular, pelo pormenor macabro, 
por quadros repulsivos, onde os vilões descem à monstruosidade animalesca, e cujas fontes mais remotas podem ser procuradas na literatura estrangeira, nomeadamente nos romances setecentistas de Walpole ou ainda na vasta obra de Mrs. Radcliffe e outros tantos autores que, sobretudo a partir da década de 1830, são abundantemente traduzidos em Portugal. Porém, este tipo de literatura de lances arrepiantes, foi um fenómeno datado, muito embora tenha deixado marcas nalguns dos nomes mais sonantes da nossa literatura oitocentista de fim de século, principalmente em Camilo, Teófilo Braga e até no próprio Eça (O Esqueleto).

As cenas desenrolam-se, como já referimos, não dentro de um clima sentimental e moralizador, mas revelam a intenção de chocar, de interessar pelo excesso.

No entanto, mesmo nas duas primeiras coletâneas citadas, Pacheco Neves evidencia uma certa elasticidade em relação aos preceitos desta escola. Decididamente, o autor não se socorre mais de ambientes medievalistas, que serviam de palco à ação e alimentavam constantemente a expectativa do leitor, comprazendo-se na descrição de castelos, conventos ou prisões que escondiam infindáveis labirintos, com recantos e passagens secretas, podendo ser usados como elementos cénicos de terror. Pacheco Neves, pelo contrário, surpreende os vícios e os crimes na contemporaneidade, na rotina da vida pequeno - burguesa ou miserabilista de um Portugal rural e, geralmente, em ambientes onde a vida se perde e se degrada (como a taberna, o hospital, o cemitério).

Os seus heróis movem-se em ambientes extraídos de um meio geo-humano, assente no quotidiano, onde julgamos descortinar a própria vivência do autor, lugares esses que a memória provavelmente recuperou ou transfigurou e que segundo João Conde Veiga eram "quase sempre dentro da sua Vila do Conde, vila que agora tem direito de cidade, mas mantém a alma" ${ }^{4}$.

Mas o mais habitual é que, nos seus contos, a ação careça de referentes espaciais bem particularizados. Os elementos descritivos são meros dados de uma topografia reduzida ao mínimo. Os eventos desenrolam-se num «monte» (Zé Quinau), numa "serra» (Oiro Negro), num «jardim com tílias» (O Cego do Jardim), na "casa do abade» (Por Mal fazer, Bem Haver...), na "quitanda" (Vingança de Bêbedo), ou circunscrevem-se a uma "povoação» indefinida. Em grande parte,

4 João Conde Veiga, "Para uma situação literária de Joaquim Pacheco Neves», Boletim Cultural da Câmara Municipal de Vila do Conde, nova série, n. ${ }^{\circ}$ 20, 11 junho de 1998, p. 23. 
pois, os espaços são telúricos mas não miudamente dilucidados. O leitor não tem certezas taxativas sobre o local onde tudo se vai passar.

Episodicamente, o cenário onde decorre a ação, se bem que abstrato, pode apontar para uma "tasca de comes e bebes lá para as bandas do Suajo», ou o contexto indiciar ou aludir, sem insistir em datas ou lugares, a uma qualquer aldeola minhota pela fugidia referência às "litradas do verde»" que jorram da caneca do taverneiro para a goela dos incorrigíveis bêbedos. Porém, contrariamente aos quadros que Júlio Dinis poetizara, Pacheco Neves apresenta-nos, nestas duas obras, o reverso da vida rústica.

Todavia, é impossível sonegar-se a infiltração dessa corrente literária tenebrosa nos contos do escritor vilacondense. Ao mundo da sua memória, num constante recurso à circularidade das leituras em que potencialmente o autor se aventurou, vêm à tona algumas das características desta estética do horrível. De facto, é de assinalar, a revalorização de ambientes sombrios e contorcidos, acentuadamente dramáticos e desconcertantes, em sintonia com a psicopatologia das personagens. Bem longe dos ideais de harmonia, serenidade, sobriedade e ordem da arte clássica, nestas duas coletâneas mergulhamos na obscenidade, em factos grosseiramente vulgares e sórdidos, a que a própria natureza da paisagem parece muitas vezes associar-se. Na fronteira da irrealidade, o nosso autor cria um universo ciclónico, transfigurado por horríveis tempestades, num fundo de frenesi trágico e de morte:

«Cá fora, a noite apresentava-se borrascosa. O vento sibilava canções macabras e a chuva caía a espaços em grossas bátegas que ensopavam a terra e a quem se atrevia a caminhar desprevenido nas ruelas. Ao longe, os relâmpagos recortavam, no fundo sombrio da escuridão, os contornos do casario e davam às árvores oscilantes o espectral esfumado das formas imprecisas dos duendes.

- A noite está d'apetite. - resmungou o Malhão, erguendo a gola do casaco e enterrando o boné até às orelhas.» ${ }^{7}$

\footnotetext{
5 Contos Sombrios, ed. cit., p. 131.

6 Contos Macabros, ed. cit., p. 41.

7 Id.,
} 
Não raro, a função do enquadramento, quando expresso, reside na criação de um locus horrendus, tópico oposto ao ideal renascentista do locus amoenus. Estamos perante um cenário de angústia, estreitamente correlacionado com a mundividência das personagens e com os temas que estruturam a narrativa. O contexto situacional gera, assim, apesar de muito parcimonioso, significados simbólicos indispensáveis para compreendermos as personagens e as suas ações.

Não obstante estas reminiscências ou adornos "negros", que aqui e ali ainda ressoam, tais como o aproveitamento estilístico de expressões como "os pios agoirentos das corujas" ${ }^{8}$ e as sombras "esguias de ciprestes", (a lembrar O Noivado do Sepulcro de Soares de Passos), ou ainda noutro plano de análise, o tema do marido que volta após uma longa ausência para vingar a sua honra (Ódio Velho), parece-nos particularmente tendencioso tratar estes contos como meras reabilitações da literatura gótica.

Sem prejuízo do relevo de que desfrutam os fatores invocados, importa também chamar a atenção para a elaboração específica das histórias e o modo como elas nos são narradas. A produção literária de Joaquim Pacheco Neves assenta, de modo nítido, numa estética da objetividade, visto o narrador se limitar, com frequência, a expor os acontecimentos em vez de os comentar ou de se alongar em explicações e interpretações. Veja-se, a este propósito, o que se passa em O Alverca (Histórias de pobres), onde o narrador, assumindo o ponto de vista da personagem, permite ao leitor tomar conhecimento de modo praticamente direto da sua perturbação interior, desencadeada pela dependência do álcool.

"O Alverca foi andando ao longo da adega e mergulhando o olhar triste nas grandes cubas preparadas para receberem o vinho. Tinham uma altura respeitável e pareciam desafiar a ação destruidora do tempo. Bateu numa com os nós dos dedos e ouviu um som claro responder ao toque. Estava vazia. Foi andando até que, de repente, deu com os olhos num garrafão manchado com borrões de vinho tinto. "Aquele é tinto", pensou." Que bem me saberiam alguns tragos!" Sem tirar os olhos do garrafão, foi andando até ficar próximo. Era como se já o tivesse nas mãos, seguro pelo gargalo, a sentir escorrer a frescura pela garganta abaixo e

\footnotetext{
$8 \quad$ Id., p. 14.

9 Contos Sombrios, ed. cit., p. 89.
} 
aquele doce canto da saída, aos glus-glus, encher-lhe a alma de alegres contentamentos. Ia pegar-lhe, mas sentiu na consciência a voz do Ribeiro recomendar-lhe: "Nada de vinho, sr. Alverca."

Fica-se, deste modo, a conhecer a personagem pelos seus atos, gestos ou diálogos, subordinando-se, por outro lado, o enunciado às suas limitações e capacidades cognoscitivas. Na maioria dos casos, o narrador dá mesmo preferência ao discurso dos seus heróis, passando estes a revelar-se e a apresentar-se.

Nesta ordem de ideias, Joaquim Pacheco Neves partilha os dogmas do princípio estético da escola naturalista a qual advogava a impassibilidade do romancista face à sua criação e que, do lado de lá dos Pirenéus, teve em Flaubert um dos mais fiéis defensores. Para além disso, convirá lembrar um outro aspeto que estrutura a obra do autor em questão. Refiro-me à mensagem ou discurso estético, enquanto reveladores de sentidos. Sem ambições de esgotar esta matéria, diríamos que é sobretudo nos contos mais tardios que Pacheco Neves projeta uma conceção determinista da existência, problemática esta posta a circular no romance naturalista e que assentava em diretrizes relativamente claras e codificadas, nomeadamente na influência do meio sobre as personagens, na atenção particular dada aos condicionamentos genéticos, no papel da educação, etc. O indivíduo era esvaziado do livre arbítrio e movia-se condicionado por forças materiais que o transcendiam, preceitos seguidos e defendidos por E. Zola. Também em P. Neves as personagens são comandadas por instintos baixos e por impulsos abismais, difíceis de refrear. O vício e as paixões mesquinhas subjugam-nas a ponto de se comportarem sem heroísmo nem virtude.

Desta forma, os heróis são definidos linearmente por um traço, por uma singular psicologia doentia e mórbida que os predispõe a cometer os crimes mais horrendos e que os acompanha durante todo o percurso narrativo. O retrato do Zé Chupado, por exemplo, é definível por um único traço ao longo da narrativa: o bêbedo crónico e de maus instintos "de alma entorvecida ao léu, pelos fumos do álcool que the enublavam a razão.»" ${ }^{11}$. O podador de Ódio Velho, também ele beberrão, é dominado pelo ódio e pela sede de vingança. O herói de O Pulso

10 Histórias de Pobres, ed. Ser, 1978, p. 34.

11 Contos Macabros, ed. cit., p. 96. 
sucumbe ao peso das suas crises de hipocondria. Em A Ti Maria Migalhas (Histórias de Pobres), a cobiça conduz à profanação do túmulo. Em O Pilha Galinhas (Histórias de Pobres), a preguiça espera o momento oportuno para transformar o homem em larápio. Governadas, especificamente, pelas pulsões mais materiais e cegas, as personagens são conduzidas a praticar atos de crueldade física ou psíquica e surgem como que alienadas de si próprias, parecendo obedecer a um rigor dedutivista e a uma mecânica montada por uma ideia fixa e diabólica.

Sem hesitações e sem dilemas de consciência, o vício progride alimentado ou intensificado, não raro, pelo uso do álcool. A bebida cumpre, assim, a sua função de estimulante psíquico, não geradora de paraísos artificiais como em Baudelaire, mas revelando ser, pelo contrário, uma ponte para o mundo insondável do mal, para o ressurgir do "monstro» e do animal que habita em toda a aparência humana, paradigma a que obedeciam também já as personagens de Edgar Poe.

Nos Contos Sombrios, Zé Quinau, Zé Grosso, a Ti Ana, e outros tantos heróis, não evolucionam no decurso da narrativa e, por isso, também não surpreendem o leitor com as suas ações destrambelhadas. Como fantoches, os protagonistas conservam o essencial da vida mas, encarados sob certo ângulo, revelam apenas ser joguetes manobrados por meio de um cordel de obsessões que, duradouramente, os dominam.

Este tipo de motivação correlaciona-se, como é óbvio, com os princípios que o naturalismo advoga, ou seja, o fatalismo da sujeição do homem a forças que o transcendem tais como: o ódio, a vingança, a sede do lucro, a luxúria, o crime, o suicídio, em suma, a violência das paixões mais condenáveis. Numa visão contorcida da vida, Pacheco Neves exprime, portanto, a imperfeição dos seres, não como um moralista, mas antes como um anatomista que procede à dissecação apenas para nos causar repulsa.

Porém, o que, em nosso entender, mais avulta nestas coletâneas é a estranha e, por assim dizer, quase insustentável exibição da morte, acentuada pela singularidade dos motivos que a instalam aos olhos do leitor, tais como o macabro, a decomposição do cadáver, as agonias do envenenamento e outras formas de exibir a passagem da vida para a representação, em toda a sua crueza, do cadáver. O autor, hiperboliza a realidade com toda a sua fealdade e imperfeição, afastando-se assim, de um idealismo que exclui tudo o que é grosseiro e hediondo. 
Em nome desse princípio, o escritor vilacondense multiplica a morte a cada página da sua obra. Ela orquestra os doze contos da coletânea Contos Sombrios e o seu domínio estende-se também aos Contos Macabros e a outros textos mais tardios. Nos episódios trágicos que a sua escrita traça, sem temperos, morre-se de todos os modos e feitios. Por doença ( $A$ morte do enfermeiro, $A$ morte do cadáver, A volta à vida), por suicídio (O paralítico, A serrana, Diário de um suicida), por assassinato (A morte do Pisco, Vingança de bêbedo, Zé Quinau, Uma história sem importância, A loucura do Migas), por acidente (O sacrista bebedola, O vôo do moscardo) e até por excesso de imaginação e de cobiça (O pulso, Oiro negro). Tratada com uma crueza sem freio, a morte assemelha-se, nas narrativas deste autor, não raro, à poesia barroca no que ela encena de mais perturbante e teatral.

A morte, nos contos de Pacheco Neves não é, pois, o repouso desejado, mas golpe violento, pesadelo de mortos e vivos. Minuciosamente detalhada, a visão tende a suplantar a realidade e transforma em espetáculo repugnante o cadáver:

"Olhou-lhe para a barriga esventrada, a tufar as tripas pela abertura; para a bôca esborrachada, por onde espreitava a língua inchada e negra; para os ossos da cara, encunhados na massa branca do cérebro; para o ôlho cèguêta revirado e fito no céu, lá distante. E sentiu nojo daquele ruim aspecto que o obrigava a cuspir enauseado e a abandonar, numa fuga, aos bicos vorazes dos abutres, os dois cadáveres que a morte irmana na mesma cova assassina.» ${ }^{12}$

O narrador, sem qualquer tendência moralizadora ou depuradora face às desgraças que se abatem sobre as personagens, não desencadeia qualquer tipo de compaixão no leitor. Antes pelo contrário, uma estranha náusea invade o espírito perante o estrebuchar da vítima e, especialmente, quando a morte se tinge de "putrefação", num descarnado realismo de rara violência.

A tradicional serenidade no morrer, que marca a atitude dos homens até aproximadamente à época do Romantismo, é substituída, na obra de Joaquim Pacheco Neves, pelo pavor da certeza do destino cruel que se esconde em todo o homem.

12 Contos Sombrios, Prefácio de José Régio, ed. cit., pp. 14 e 15. 
Lévi-Strauss, a quem se devem importantes estudos sobre esta matéria, lembra que no imaginário cultural (especialmente a partir do século xviII), a morte é suja, e o sujo é o mal. Simbolizando o surgimento do «não cultural», da «não civilização", o cadáver será, por isso mesmo, mantido à distância, no lugar que a comunidade lhe reservou: o cemitério e a lápide que lhe dá o remate final. Só aí a morte passa a ser aceitável.

Mas, uma leitura atenta dos textos de Pacheco Neves torna também muito notória a interação existente entre esta estética do excesso e a propensão para chocar, nomeadamente, graças ao recurso a um vocabulário de grande trivialidade que vem quebrar o trágico das situações e lhes empresta um toque humorístico. Por isso, José Régio com muita perspicácia, na nota introdutória que fez aos Contos Sombrios, chama a atenção do leitor para o "humorismo no funéreo", ou seja, para essa "espécie de bonomia sarcástica ou familiaridade desconcertante; o da ironia, ou do quer que seja vizinho, perante os seus próprios assuntos e inclinações ${ }^{13}$. Eis como Pacheco Neves, no texto O vôo do moscardo, num crescendo de detalhes amplificadores, exagera a descrição do repelente corpo do moscardo assassino:

«Era feio o moscardo e mais se afeiara, no entender do Marques, quando o viu estorcer os aneis do corpo, imbricá-los numa ansa, afunilá-los na postura dejectante e largar fezes sôbre o seu ventre largo e obeso.» ${ }^{14}$

Esta precisão tinge-se de um gozo cómico que oscila entre a gravidade e a banalidade, lembrando o traço a vitríolo dos grandes caricaturistas da imprensa do século XIx. A morte assemelha-se, assim, nestes contos, à "paródia carnavalesca» estudada por Bakhtine. Recordemos, a título de exemplo, a ridícula comicidade que o autor tira do trágico fim do homem, objeto nas mãos do seu semelhante e, por fim, repasto dos vermes na sepultura. Eis como em Contos Sombrios, o Verme, resume, com minúcia, ao Cadáver, a sua tarefa na decomposição:

13 Contos Sombrios, ed. cit., p. 153.

14 Id., p. 80. 
"Como o tempo para nós nada representa, esperamos que as pessoas que envolveram o defunto nessa mortalha dura, morram. Se ainda não basta, aguardamos que se finem os novos descendentes, porque à terceira ou quarta geração, quando os laços afectivos se distendem pela falta de conhecimento entre uns e outros, podemos ter a certeza que se vão ao chumbo, desencarapaçam o morto, põem o caixão na terra e esperam que façamos o trabalhinho depressa, para o novo hóspede cair na toca.» ${ }^{15}$

Segundo Jean Château, o humor poderá ser perspetivado como «un mixte de sérieux et de non sérieux" ${ }^{16}$. Em Pacheco Neves, o tom "sério» que predomina em certas cenas macabras não impede que, aqui e ali, o texto se deixe invadir por processos de pendor humorístico, numa tensão que ressoa a provocação. É que, de facto, o humor coexiste, nos seus contos, com a presença de factos mórbidos, com a encenação escancarada da morte, ou dos estados que lhe são próximos, como a agonia, ou seja, esse tempo que separa a morte da vida, a vitalidade do corpo, do estatismo do cadáver. Graças à inclusão de elementos humorísticos, o medo insustentável da morte parece esbater-se. A morte é colocada à distância. O autor como que corrige o arrojo de algumas cenas e o aspeto mais bestial e hediondo da morte recorrendo ao poder da imagem forte e sarcástica. É neste interseccionismo de "signos contraditórios", que se revela claramente o jogo funebremente cómico da prosa de Pacheco Neves. A nível da linguagem, o autor procura o vocábulo frio e cru, não raro de inspiração médica, a notação neutral, que contrabalança com a exuberância e o poder expressivo das imagens e do pormenor, como o uso dos particularismos regionais, os quais estabelecem um violento contraste com o princípio anterior. Citemos uma passagem do desfecho trágico-cómico do Sacrista bebedola preso no fogo que ele próprio ateou:

"Os fumos do vinho, varridos pela sudação forçada, deixaram-no calcular o perigo. Num lampejo de raciocínio pareceu-lhe encontrar uma aberta para escapar à fogueira, escorregando pelo telhado, até encontrar a firmeza da parede mestra do lado da sacristia. Mas, quando lhe acudiu o pensamento, a trave onde estava, roída

15 Jean Château, "Le sérieux et ses contraintes", Revue Philosophique, no 10-12, 1950, p. 10.

16 Contos Macabros, ed., cit., p. 15. O sublinhado é nosso. 
pelo fogo, abateu e engoliu na fornalha o corpo vivo que nela se encarrapitava. O grito foi abafado pelo fragor da derrocada; mas as chamas, quando o corpo do sacrista se reduziu a torresmos, cresceram e brilharam mais espertas. ${ }^{17}$

A ousadia das metáforas e das comparações, discretamente pejorativas e desapaixonadas sobre a sorte da personagem, fazem-nos retomar o contato com a realidade e, em última análise, parecem expurgar a morte da vida. A linguagem humorística desrespeita a exigência da arte realista, acalma os nervos, criando um clima de quase prosaísmo que se opõe à angústia e ao medo do violento, do anómalo e do asqueroso como se verifica neste outro excerto:

"O Brás e a amásia, ao ver entre portas o Quinau, ficaram aterrados e não detiveram o grito de pavor que lhes subiu às gargantas. Refugiaram-se num canto da casa a bradar por socorro. Mas, antes que acudissem gentes, as mãos do Quinau filou-os pelos gorgomilos e fêz embater os corpos como pratos de filarmónica de aldeia.» ${ }^{18}$

Através do humor, Pacheco Neves alivia a tensão e a repulsa que causam as imagens violentas da morte e que a sua escrita pôs a nu, retalhando e descosendo fibra a fibra, sem condescendência. Assim, a veia humorística revela ser o caminho mais seguro para que autor e leitor se distanciem das personagens, das suas misérias e podridões e, consequentemente, do pavor que constitui a passagem da vida à morte.

Assim, muito embora quase todos os contos do escritor vilacondense terminem tragicamente com a morte dos heróis, poderemos perguntar-nos se a veia humorística que se vem imiscuir no horrível enredo fúnebre não funcionará, afinal, como afirmação da vida. O humor em Pacheco Neves seria, desta forma, a porta de saída que o autor encontrou para afirmar a vida. Ao escrutar ostensivamente o corpo doente ou empastado pelo sangue da violência, ao acumular pormenores ligados à degradação do próprio cadáver, Pacheco Neves, o médico de profissão, exerce também na escrita, a que consagrou grande parte do seu

17 Contos Sombrios, ed., cit., p. 33. O sublinhado é nosso.

18 Contos Sombrios, ed., cit., p. 33. O sublinhado é nosso. 
tempo de lazer, o seu olhar realisticamente clínico, diagnosticando a morte nos "Outros». Se bem que a consciência da sua própria condição de mortal o tenha, provavelmente, levado a obedecer, simultaneamente, a um impulso contraditório e, como se de um espelho se tratasse, as suas histórias escondem, nos artifícios das imagens cruéis, na linguagem contorcida, nas antíteses violentas e abruptas, o medo e o fascínio do seu próprio fim. 